\title{
SIMULTANEOUS DETERMINATION OF ACESULFAME-K, ASPARTAME AND STEVIOSIDE IN SWEETENER BLENDS BY ULTRAVIOLET SPECTROSCOPY WITH VARIABLE SELECTION BY SIPLS ALGORITHM
}

\author{
Yang-Chun He, Sheng Fang*, Xue-Jiao Xu \\ College of Food Science and Biotechnology Engineering, \\ Zhejiang Gongshang University, Hangzhou 310035, China \\ fszjgsu@gmail.com
}

\begin{abstract}
A chemometric-assisted UV absorption spectroscopic method is proposed for the simultaneous determination of acesulfame-K, aspartame and stevioside in raw powder mixtures of commercial sweeteners. The synergy interval partial least squares (siPLS) algorithm was applied to select the optimum spectral range and their combinations. The utilization of spectral region selection aims to construct better partial least squares (PLS) model than that established from the full-spectrum range. The results show that the siPLS algorithm can find out an optimized combination of spectral regions, yielding lower relative standard error of prediction (RSEP) and root mean square error of prediction (RMSEP), as well as simplifying the model. The RMSEP and RSEP obtained after selection of intervals by siPLS were $0.1330 \mu \mathrm{g} \cdot \mathrm{ml}^{-1}$ and $1.50 \%$ for acesulfame-K, $0.2540 \mu \mathrm{g} \cdot \mathrm{ml}^{-1}$ and $1.64 \%$ for aspartame, $1.4041 \mu \mathrm{g} \cdot \mathrm{ml}^{-1}$ and $2.03 \%$ for stevioside respectively. The recovery values range from $98.12 \%$ to $101.88 \%$ for acesulfame-K, $98.63 \%$ to $102.96 \%$ for aspartame, and $96.38 \%$ to $104.04 \%$ for stevioside respectively.
\end{abstract}

Keywords: acesulfame-K; aspartame; stevioside; synergy iPLS; UV absorption spectroscopy; wavelength selection

\section{ИСТОВРЕМЕНО ОПРЕДЕЛУВАҢЕ НА АЦЕСУЛФАМ-К, АСПАРТАМ И СТЕВИОЗИД ВО ЗАСЛАДУВАЧИ СО УЛТРАВИОЛЕТОВА СПЕКТРОСКОПИЈА СО ИЗБОР НА ПРОМЕНЛИВИ СО АЛГОРИТАМОТ SIPLS}

Предложен е хемометриски помогнат метод за истовремено определување на ацесулфам-К, аспартам и стевиозид во засладувачи со ултравиолетова апсорпциона спектроскопија во реални смеси на комерцијални засладувачи. Алгоритмот со синергиски интервал на парцијални најмали квадрати (siPLS) е применет за избор на оптимална комбинација и на спектрална област. Изборот на оптималната спектрална област помага да се конструира подобар модел на методот за парцијални најмали квадрати (PLS) во однос на оној за целата спектрална област. Резултатите покажуваат дека со алгоритмот siPLS можат да се најдат најпогодните комбинации од спектрални области со кои се добиваат помали стандардни грешки за процена на резултатите (RSEP) и средноквадратни грешки за процена (RMSEP), како во едноставниот модел. Добиените RMSEP и RSEP по изборот на спектралните области со siPLS се $0,1330 \mu \mathrm{g} \cdot \mathrm{ml}^{-1}$ и $1.50 \%$ за ацесулфам-K, 0,2540 $\mu \mathrm{g} \cdot \mathrm{ml}^{-1}$ и $1,64 \%$ за аспартам, 1,4041 $\mu \mathrm{g} \cdot \mathrm{ml}^{-1}$ и 2,03 \% за стевиозид. Аналитичкиот принос се движи од 98,12\% до 101,88 \% за ацесулфам-К, од 98,63 \% до 102,96 \% за аспартам и од 96,38 \% до 104,04\% за стевиозид.

Клучни зборови: ацесулфам-K; аспартам; стевиозид; синергиски iPLS; UV апсорпциона спектроскопија; избор на бранова должина 


\section{INTRODUCTION}

Artificial sweeteners with lower calorie benefit people who have problems with sugar metabolism. They are also cheaper and can significantly reduce the manufacturing costs of some beverages and food products. Nowadays, the common trend in food industry is to use sweetener combinations, as so-called blends, to take advantage of the synergism that occurs with these combinations and to provide certain sensory profile $[1,2]$. In the case of sweetener blends manufacturing, the control of sweeteners proportion in blends is essential to precisely reproduce the texture, sweetness profile and also reduce the adverse health effects [3]. Therefore, fast and accurate methods to assure quality control and product integrity are essential to meet the needs of growing market of sweetener blends $[4,5]$.

Several methods have been described to determine artificial sweeteners separately or in combination. Most of the methods reported so far are based on high-performance liquid chromatography (HPLC) techniques [6-8]. Also, as an alternative to classical HPLC methods, ion-exchange chromatography (IC) has been successfully used for the analysis of different sweeteners $[9,10]$. In addition, capillary (zone) electrophoresis [11] and Fourier transform infrared (FTIR) spectroscopy with organic solvent extraction [12] have been applied to the simultaneous determination of several kinds of sweeteners. However, most of these methods are suitable for the analysis of sweeteners in foods and soft drink samples, but they require rather expensive analytical instruments and higher running costs because of the need of preliminary separation steps for sample preparation [13].

Multivariate calibration has been gaining importance in the resolution of multi-component mixtures in recent years. It offers the advantage of eliminating or minimizing preliminary separation steps by allowing to simultaneously determine two or more components [14, 15]. Until now, several papers have been reported to successfully using spectrophotometry with partial least squares (PLS) regression for the simultaneous de- termination of kinds of sweeteners. For example, UV-visible spectrophotometry with PLS was applied to the simultaneous determination of binary mixtures containing saccharin and aspartame [5], acesulfame-K and aspartame [16], saccharin and acesulfame-K [17], or ternary sweetener mixtures containing aspartame, acesulfame- $\mathrm{K}$ and saccharin [18], acesulfame-K, sodium cyclamate and saccharin sodium [19]. Procedures based on FT-Raman spectroscopy with chemometrics have also been successfully developed for sweeteners $[20,21]$. However, all these methods used information from the whole spectrum region measured to build a calibration model.

It has been demonstrated, both theoretically and experimentally, that performing spectral region selection can still considerably refine the performance of these full-spectrum calibration procedures [22, 23]. Many algorithms have been proposed for the selection of characteristic wavelength, such as moving windows [24-26], interval PLS (iPLS) [27, 28], genetic algorithms [29, $30]$, and ant colony optimization $[31,32]$. Recently, a moving windows based variable selection method with varied window size has been proposed by our group that suitable in potentiometric titration multivariate calibration [25]. However, among the different types of utilization methods, the iPLS method has gained much attention due to its high efficiency and ability to represent results in a graphical manner, focusing on models with specified intervals and interpretation. The main principle of this method is to develop PLS regression model in smaller equidistant spectra regions using the same or less number of latent variables. In recent years, many successful applications of iPLS based methods have been reported in the literature [33-36].

In this work, the iPLS and synergy interval partial least squares (siPLS) methods in combination with ultraviolet spectroscopy were applied to the simultaneous determination of acesulfame-K, aspartame and stevioside in raw powder mixtures of commercial sweeteners. The siPLS method was applied to select the optimal spectral region and their combinations, with which one could establish a more stable and accurate calibration model. 
An independent set of samples was employed to evaluate the prediction ability of the full-spectrum PLS and siPLS models. The results demonstrated that the siPLS algorithm could be successfully applied to the simultaneous determination of three sweeteners, without the HPLC separation step, in the routine quality control during the manufacture of sweetener blends.

\section{EXPERIMENTAL}

\subsection{Chemicals and standard solutions}

All the chemicals used were of analytical reagent grade. The pure acesulfame-K was obtained from the National Research Center for Certified Reference Materials of China (Beijing) and was used as received. Aspartame and stevioside as standard materials were kindly supplied by the Key Laboratory of Pharmaceutical Engineering of Ministry of Education, Zhejiang University of Technology (Hangzhou). Pure water was produced by Nanopure Diamond UV/UF water purification system (Thermo Scientific Barnstead, USA). Standard working solutions at the desired concentrations were prepared daily by appropriately diluting stock solutions in water. These sample solutions were kept in air-tight stoppered glass bottles. The masses were weighed on an Ohaus balance to an accuracy of $\pm 0.01 \mathrm{mg}$.

\subsection{Instrumentation and software}

A UV/Visible spectrophotometer (UV2250, Shimadzu, Japan) with automatic wavelength correction and wavelength repeatability was employed for all the measurements. The spectral data were recorded by using the UV Probe software.

Programs for performing PLS regression and cross validation were written in Matlab. The iToolbox [27, 28] for Matlab (http://www.models. kvl.dk, USA) was used for variable selection and development of the multivariate models iPLS, and siPLS.

\subsection{Procedure}

The orthogonal experimental design was used to statistically maximize the spectrum information content in the calibration set. As shown in Table 1, the acesulfame-K, aspartame, and stevioside concentrations for the standard calibration set were varied between 4.73-18.92, 5.39-21.56 and $21.88-87.52 \mu \mathrm{g} \cdot \mathrm{ml}^{-1}$, respectively. These mixed standard solutions were placed in a $10-\mathrm{ml}$ volumetric flask, and dilute to mark with distilled water. Each solution was transferred to a $1 \mathrm{~cm}$ path length quartz cell for spectral measurements, which were made against the blank solutions. The absorption spectra were recorded between 200 and $400 \mathrm{~nm}$ with fixed slit width of $2 \mathrm{~nm}$.

Table 1

Concentrations of the different sweereners in the calibration set

\begin{tabular}{ccrc}
\hline \hline \multirow{2}{*}{$\begin{array}{c}\text { Sample } \\
\text { number }\end{array}$} & \multicolumn{3}{c}{ Concentration $\left(\mu \mathrm{g} \cdot \mathrm{ml}^{-1}\right)$} \\
\cline { 2 - 4 } & Acesulfame-K & Aspartame & Stevioside \\
\hline C1 & 4.73 & 5.39 & 21.88 \\
C2 & 4.73 & 10.78 & 43.76 \\
C3 & 4.73 & 16.17 & 65.64 \\
C4 & 4.73 & 21.56 & 87.52 \\
C5 & 9.46 & 5.39 & 43.76 \\
C6 & 9.46 & 10.78 & 21.88 \\
C7 & 9.46 & 16.17 & 87.52 \\
C8 & 9.46 & 21.56 & 65.64 \\
C9 & 14.19 & 5.39 & 65.64 \\
C10 & 14.19 & 10.78 & 87.52 \\
C11 & 14.19 & 16.17 & 21.88 \\
C12 & 14.19 & 21.56 & 43.76 \\
C13 & 18.92 & 5.39 & 87.52 \\
C14 & 18.92 & 10.78 & 65.64 \\
C15 & 18.92 & 16.17 & 43.76 \\
C16 & 18.92 & 21.56 & 21.88 \\
\hline \hline
\end{tabular}


Another seven samples that were not included in the calibration set were prepared as an independent test set (named the prediction set). The procedure for preparation of each solution in the prediction set is similar to the calibration set. These solutions were measured using UV/Visible spectrophotometer under the same condition. Both the calibration and prediction spectra were preprocessed by Savitzky-Golay smoothing [37].

\subsection{Data analysis}

Chemometrics models were applied to obtain quantitative information from the spectra of mixtures. Generally for the evaluation of the error of each model and to find the optimum number of latent variables, the root mean square error of cross validation (RMSECV) and root mean square error of prediction (RMSEP) can be used $[38,39]$ :

$$
\operatorname{RMSECV} / \mathrm{P}=\left[\frac{1}{n} \sum_{i=1}^{n}\left(c_{\mathrm{i}}-c_{\mathrm{i}, \mathrm{pred}}\right)^{2}\right]^{1 / 2}
$$

Also, to evaluate the predictive ability of a multivariate calibration model, the relative standard error of prediction (RSEP) was checked as calculated from the following equation:

$$
\mathrm{RSEP} \%=\sqrt{\frac{\sum_{i=1}^{n}\left(c_{\mathrm{i}}-c_{\mathrm{i}, \text { pred }}\right)^{2}}{\sum_{i=1}^{n}\left(c_{\mathrm{i}}\right)^{2}}} \times 100
$$

where $c_{\mathrm{i}, \text { pred }}$ is the predicted value, $c_{\mathrm{i}}$ is the reference value of $i$ sample and $n$ is the number of samples.

\section{RESULTS AND DISCUSSION}

Figure 1 shows the UV spectral characteristics of pure acesulfame-K, aspartame and stevioside. As can be seen in the Figure 1, acesulfame-K shows an absorption maximum at about $\lambda=226 \mathrm{~nm}$. The maximum absorption wavelengths for both aspartame and stevioside are all approximately $200 \mathrm{~nm}$, and the absorption decrease as the wavelength increase between 200 and $220 \mathrm{~nm}$ linearly with almost the same slope. On the other hand, stevioside shows an absorption shoulder at about $\lambda=235$ $\mathrm{nm}$ which is overlapped by the absorption of acesulfame-K. It can be found that the curves of all these three species are overlapped and affected each other, so they can not be determined by the univariate calibration procedure. Under these conditions, multivariate calibration methods can be applied to simultaneously determine acesulfame-K, aspartame and stevioside in mixtures, which allows one to eliminate or minimize preliminary separation steps.

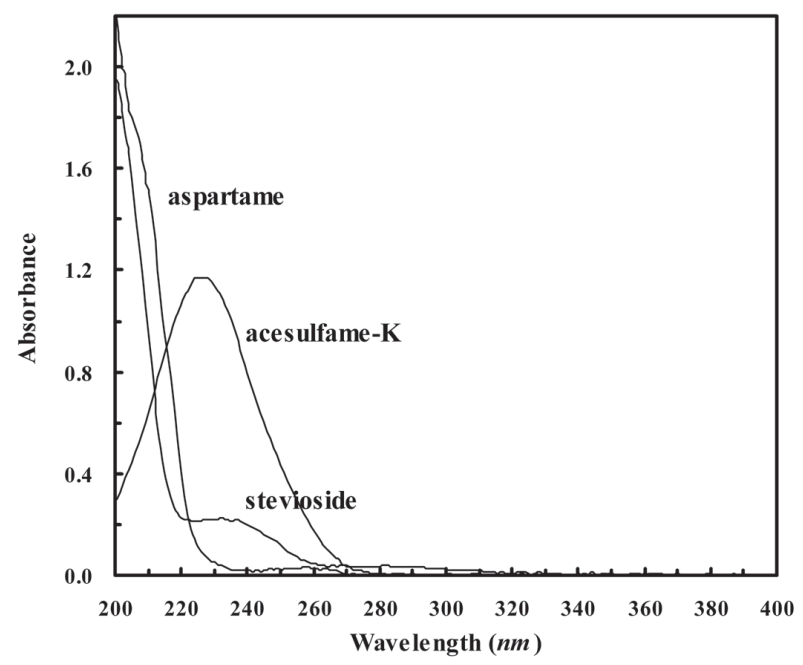

Fig. 1. The ultraviolet absorption spectra of pure acesulfame-K, aspartame and stevioside in water. The concentration of acesulfame- $\mathrm{K}$, aspartame and stevioside are $21.28,48.74$ and $209.0 \mu \mathrm{g} \cdot \mathrm{ml}^{-1}$, respectively.

\subsection{Experimental design and preprocessing choice}

All the concentrations in the calibration set were shown in the Table 1. Four levels for each sweetener were selected and 16 standard three component mixtures were prepared according to four-level orthogonal experimental design. It has been widely recognized that using such a design as the training set, maximum 
information for each component can be obtained by using only a few calibration solutions [40-42]. On the other hand, seven samples in the prediction set were randomly selected and all the artificial sweeteners lie in their concentration range tested.

It is well known that the preprocessing of spectra was found necessary to develop reliable and stable calibration models. In this work, the simple Savitzky-Golay (SG) smoothing method [37] was used. The SG algorithm can be controlled with two parameters, namely, the frame size $\mathrm{M}$ and the polynomial order K. High polynomial orders and small frame sizes yield flexible smoothing, whereas low polynomial degrees and large frame sizes may yield rigid smoothing. In this work, the root mean square error (RMSE) for the calibration set by full spectrum PLS regression were calculated and compared as a criterion under different polynomial order $\mathrm{K}$ and frame size $\mathrm{M}$. However, we established that it was difficult to find a global optimized combination between the two parameters $\mathrm{K}$ and $\mathrm{M}$ for all the three compounds simultaneously. Finally, a relatively optimized combination of $K=2$ and $M=9$ was chosen, although somewhat arbitrary, and was a good compromise in practice. It was found that the absorption in the region between 300 and $400 \mathrm{~nm}$ was negligible, so only the wavelength between 200 and 300 $\mathrm{nm}$ was shown and considered for the next full PLS and siPLS modeling.

\subsection{Full-spectrum PLS regression}

At first, the full spectrum PLS models were established in order to yield a general measurement of the wavelength selection methods. The commonly used leave-one-out cross-validation (LOOCV) method was used to select the optimum number of factors in the PLS model. In the LOOCV method, first, one sample was selected out from the total set used for validation, and then, the calibration model was constructed with the remaining samples. The procedure was repeated for all samples for the initial number of factors, and the error expressed as the prediction residual error sum of squares (PRESS) was calculated. Then, for the next number of factor, the PRESS was calculated again and up to all the factors (eight in this work) that were used. Finally, the PRESS as a function of factor numbers was obtained. It is expected that the optimal number of factors corresponds to the minimum PRESS value. However, in many cases the minimum PRESS value may cause overfitting, since there are a finite number of samples in the calibration set [43]. To find solution to this problem, the Fstatistical test suggested by Haaland and Thomas [44] was used. As suggested by Haaland and Thomas, an F-ratio probability of 0.75 $(\alpha=0.25)$ is empirically selected in this work for the full-spectrum PLS modeling.

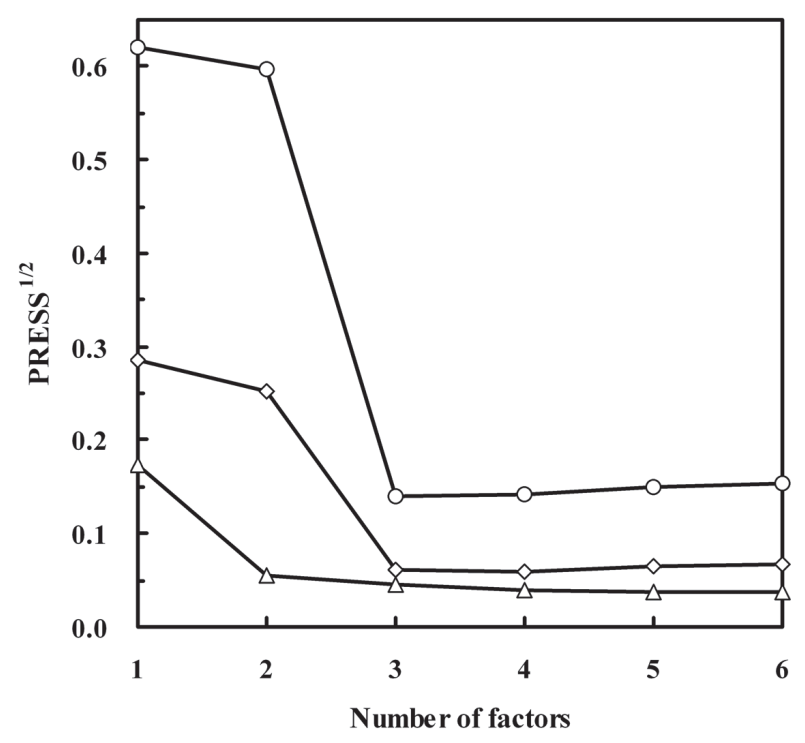

Fig. 2. Plots of PRESS $1 / 2$ vs. the number of factors by PLS with full spectrum for acesulfame-K $(\Delta)$, aspartame $(\diamond)$, and stevioside $(\circ)$, respectively.

In our case, as shown in Figure 2, it was interesting to find that the optimal number of factors obtained by this method was three for all the compounds. Results of RMSECV for the full spectrum PLS modeling were shown in Tables 2, 3 and 4 for acesulfame-K, aspartame and stevioside, respectively. In Tables 5 and 6, the error of each sweetener including RMSEP and $\mathrm{RSEP} \%$ for the prediction of synthetic mixtures 
based on the full spectrum PLS modeling was also calculated for comparison and statistical purposes.

\subsection{Wavelength selection by synergy interval PLS}

It has been demonstrated that wavelength selection is potentially able to improve the prediction ability by finding out an optimized combination of the informative regions. In this work, the optimization of spectral informative regions was accomplished by the iPLS and siPLS methods [45].

\subsection{1. siPLS model for acesulfame-K}

Firstly, the spectrum region was divided into 16 equidistant subintervals by the iPLS algorithm. For all the 16 subintervals, a calibration model based on PLS using different numbers of latent variables was developed. The RMSECV was calculated as a critical value for comparison of these models in relation to the whole spectrum model. Figure 3 shows the RMSECV for each interval selected (bars) and latent variables for each model represented by numbers above interval wavelengths, and the RMSECV for the full spectrum model (dotted line) using three latent variables. It was found that the developed model using interval number 3 with wavelengths between 214 and $221 \mathrm{~nm}$ gave the minor RMSECV values with 0.1513 , which was better than the full-spectrum PLS model with 0.1714 as shown in Table 2. Although other wavelength selection algorithms can also locate at information regions, such as genetic and ant colony algorithms, the iPLS strategy can deal with much more wavelengths and require less computing time [46]. In addition, the iPLS toolbox is more easy to use with a graphically-oriented interface.

Base on the subinterval number 3 with the smallest RMSECV, different combinations

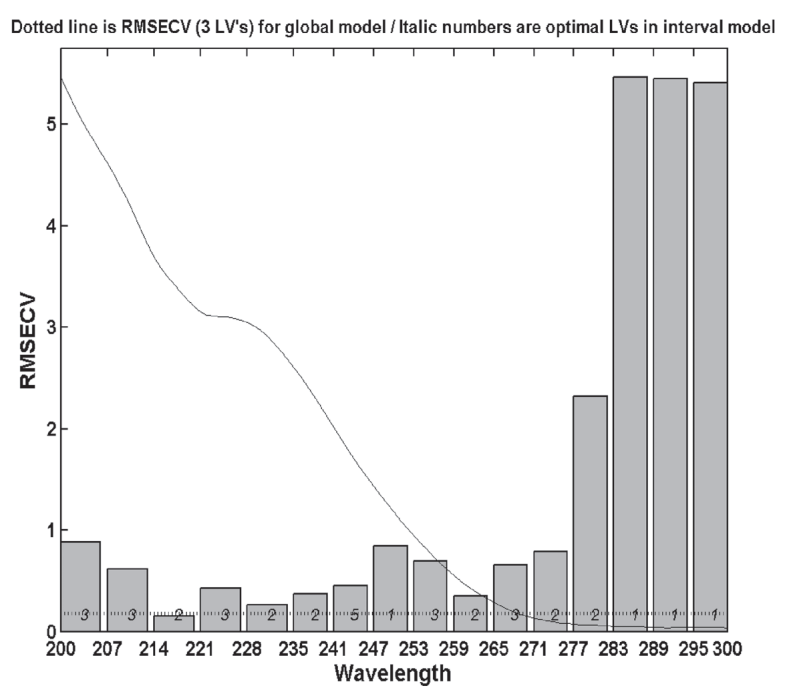

Fig. 3. Cross-validated prediction errors (RMSECV) for 16 interval models (bars) and full-spectrum model (dotted line) versus interval number for one to five latent variables in the localized models and three latent variables for the global model, for acesulfame-K determination

of intervals were tested by means of the siPLS algorithm. The statistical results of different combinations are shown in Table 2. As can be seen in the table, the combination of subintervals 3, 5 and 6 gives the lowest RMSECV with

Table 2

Statistical results of siPLS model for acesulfame- $K$

\begin{tabular}{|c|c|c|c|c|}
\hline Model & Intervals & Wavelength & $\mathrm{LV}^{a}$ & $\begin{array}{c}\mathrm{RMSE} \\
\mathrm{CV}^{b}\end{array}$ \\
\hline PLS & All & $200-300 \mathrm{~nm}$ & 3 & 0.1714 \\
\hline iPLS & 3 & $214-221 \mathrm{~nm}$ & 2 & 0.1513 \\
\hline siPLS & $3,4,5,6$ & $214-241 \mathrm{~nm}$ & 3 & 0.1395 \\
\hline siPLS & 3,5 & $\begin{array}{c}214-221 \& \\
228-235 \mathrm{~nm}\end{array}$ & 3 & 0.1514 \\
\hline siPLS & $1,2,3$ & $200-221 \mathrm{~nm}$ & 4 & 0.1789 \\
\hline siPLS & $2,3,4,5$ & $207-235 \mathrm{~nm}$ & 3 & 0.1456 \\
\hline siPLS & $3,4,5$ & $214-235 \mathrm{~nm}$ & 3 & 0.1584 \\
\hline siPLS & $3,5,6$ & $\begin{array}{c}214-221 \& \\
228-241 \mathrm{~nm}\end{array}$ & 3 & 0.1367 \\
\hline siPLS & 3,6 & $\begin{array}{c}214-221 \& \\
235-241 \mathrm{~nm}\end{array}$ & 3 & 0.1584 \\
\hline
\end{tabular}

${ }^{a} \mathrm{LV}=$ number of latent variables

${ }^{b} \mathrm{RMSE} \mathrm{CV}=$ root mean square error of cross validation 
0.1367 that are better than the subinterval 3 . The siPLS algorithm avoids the loss of relevant spectral region that will improve the performance of the calibration model.

A graphic test of model constructed by the synthetic subintervals 3,5 and 6 is shown in Figure 4. So finally, the subintervals 3, 5 and 6 , located in the 214-221 and 228-241 nm wavelength regions, were combined for the

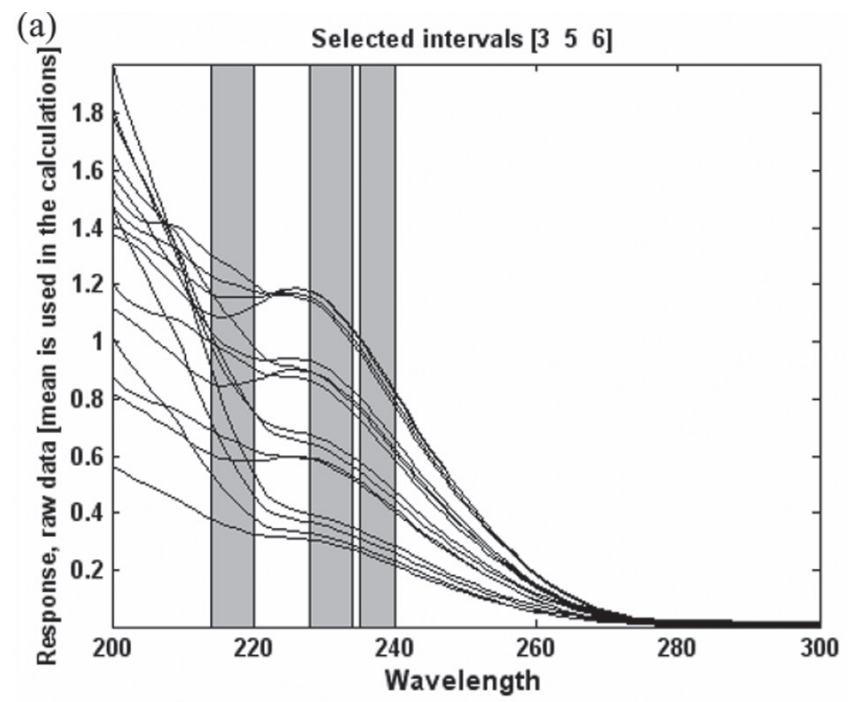

construction of calibration model in the case of acesulfame-K. It is interesting to point out that this region exactly corresponded to the absorption region of acesulfame-K within 210-240 $\mathrm{nm}$, which further confirms that the siPLS algorithm can automatically provide the correct position of the informative region for the given substance. (b) Selected intervals [ 35 6], with 3 PLS comp. for y-var. no. 1

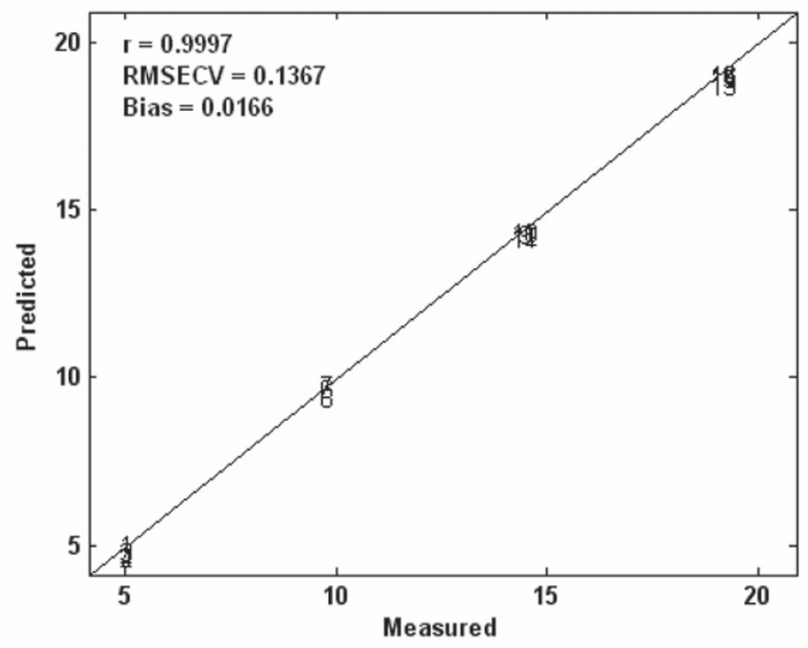

Fig. 4. Spectral regions selected to build the models and results: (a) siPLS model by combination of subintervals 3, 5 and 6 for quantification; (b) acesulfame-K content $\left(\mu \mathrm{g} \cdot \mathrm{ml}^{-1}\right)$ vs. the predicted values by cross-validation for the siPLS model with $3 \mathrm{LVs}$

\subsection{2. siPLS model for aspartame}

For aspartame, the whole spectrum was also divided into 16 equidistant subintervals. The results for each interval tested and the RMSECV for the full-spectrum based model using three latent variables are shown in Figure 5. It can be seen that the iPLS model using number 3 and 4 subintervals produce relative small RMSECV values, however it does not produce better results than the full-spectrum model. On the other hand, subintervals 1 and 2 give little bigger RMSECV values than the best result, but only with 1 latent variable. Other subinterval with the wavelength from 228 to $300 \mathrm{~nm}$ give larger RMSECV values, indicating that there is no relevant information contained in these spectral regions. These results and prior knowledge of the aspartame UV absorption spectrum indicate that a better model may be ob- tained by only using the wavelengths included in subintervals from 1 to 4 .

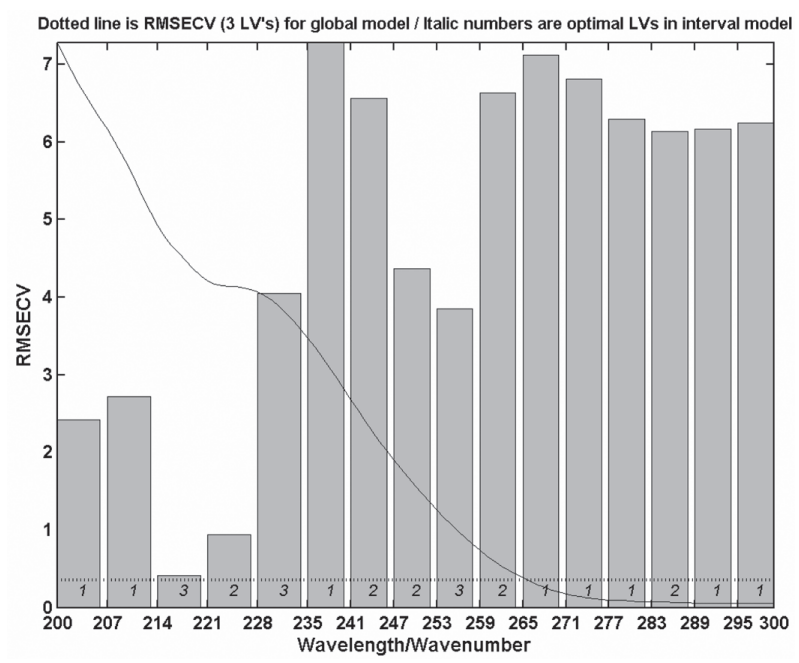

Fig. 5. RMSECV for 16 interval models (bars) and full-spectrum model (line) versus interval number for one to three latent variables in the localized models and three latent variables for the global model, for aspartame determination 
The searching of better combination of subintervals by siPLS model for aspartame confirms the above discussion. As shown in the Table 3, the combination of subintervals 1, 2, 3 and 4 give a RMSECV value of 0.3408 , better than that from the whole spectrum model. The results also indicate that introducing non-infor- mation subintervals such as number 5 into the model gives larger RMSECV value. Therefore, the siPLS models using the spectrum subintervals 1, 23 , and 4 were developed for the quantification of aspartame. The absorption wavelength regions of aspartame are also located in the $200-230 \mathrm{~nm}$ range.

T a b l e 3

Statistical results of siPLS model for aspartame

\begin{tabular}{ccccc}
\hline \hline Model & Intervals & Wavelength & LV $^{a}$ & RMSE CV $^{b}$ \\
\hline PLS & All & $200-300 \mathrm{~nm}$ & 3 & 0.3551 \\
siPLS & 3 & $214-221 \mathrm{~nm}$ & 3 & 0.4112 \\
siPLS & 1234 & $200-228 \mathrm{~nm}$ & 3 & 0.3408 \\
siPLS & 234 & $207-228 \mathrm{~nm}$ & 3 & 0.3832 \\
siPLS & 13 & $200-207 \& 214-221 \mathrm{~nm}$ & 3 & 0.3905 \\
siPLS & 123 & $200-221 \mathrm{~nm}$ & 3 & 0.4149 \\
siPLS & 34 & $214-228 \mathrm{~nm}$ & 3 & 0.4176 \\
siPLS & $1,2,3,4,5$ & $200-235 \mathrm{~nm}$ & 3 & 0.3688 \\
siPLS & 1345 & $200-207 \& 214-235 \mathrm{~nm}$ & 3 & 0.3881 \\
siPLS & 2345 & $207-235 \mathrm{~nm}$ & 3 & 0.43 \\
\hline \hline
\end{tabular}

\subsection{3. siPLS model for stevioside}

In the case of stevioside determination, Table 4 shows some selected statistical results corresponding to the comparison between different siPLS calibration models. The results show that the combination of lower number of wavelengths (subintervals 2, 3 and 6 with RMSECV of 1.0278) gives better results compared to the full spectrum PLS model. The better results obtained for subintervals 2, 3 and 6 than for 2 and 3 may be due to the fact that the stevioside absorption spectrum exhibits a shoul- der at about $235 \mathrm{~nm}$. The subinterval 6, corresponding to wavelength values between 235 and $242 \mathrm{~nm}$, contains that information area for stevioside. On the other hand, with the addition of interval number 10 (model in the intervals numbers 2, 3, 6 and 10) the RMSEP value was further reduced. So the intervals included the regions of 207-221 nm (interval 2, 3), 235-242 $\mathrm{nm}$ (interval 6) and 263-270 $\mathrm{nm}$ (interval 10) were selected to built the final siPLS model for stevioside. Good results were obtained with a correlation coefficient of 0.999 and a RMSECV value of 1.0155 . 
Table 4

\section{Statistical results of siPLS model for stevioside}

\begin{tabular}{ccccc}
\hline \hline Model & Intervals & Wavelength & LVa & $\begin{array}{c}\text { RMSE } \\
\text { CVb }\end{array}$ \\
\hline PLS & All & $200-300 \mathrm{~nm}$ & 3 & 1.2259 \\
siPLS & $2,3,6,10-15$ & $207-221 \& 235-242 \& 263-300 \mathrm{~nm}$ & 3 & 1.1747 \\
siPLS & $10-15$ & $263-300 \mathrm{~nm}$ & 3 & 10.42 \\
siPLS & $2,3,6$ & $207-221 \& 235-242 \mathrm{~nm}$ & 3 & 1.0278 \\
siPLS & $3,4,6$ & $214-228 \& 235-242 \mathrm{~nm}$ & 3 & 2.4326 \\
siPLS & $1,2,3,6$ & $200-221 \& 235-242 \mathrm{~nm}$ & 3 & 1.2177 \\
siPLS & $2,3,6,10$ & $207-221 \& 235-242 \& 263-270 \mathrm{~nm}$ & 3 & 1.0155 \\
siPLS & $2,3,6,15$ & $207-221 \& 235-242 \& 295-300 \mathrm{~nm}$ & 3 & 1.0204 \\
siPLS & $2,3,6,10,11$ & $207-221 \& 235-242 \& 263-277 \mathrm{~nm}$ & 3 & 1.0315 \\
siPLS & 2,3 & $207-221 \mathrm{~nm}$ & 3 & 1.8927 \\
siPLS & $2,3,4,6$ & $207-228 \& 235-242 \mathrm{~nm}$ & 3 & 1.0399 \\
\hline \hline
\end{tabular}

${ }^{a} \mathrm{LV}=$ number of latent variables

${ }^{b} \mathrm{RMSE} C \mathrm{CV}=$ root mean square error of cross validation

\subsection{Application to synthetic mixtures}

Table 5

Prediction set composition and their predicted values by PLS and siPLS

\begin{tabular}{|c|c|c|c|c|c|c|c|c|}
\hline \multicolumn{3}{|c|}{ Added $\left(\mu \mathrm{g} \cdot \mathrm{ml}^{-1}\right)$} & \multicolumn{3}{|c|}{ Predicted $\left(\mu \mathrm{g} \cdot \mathrm{ml}^{-1}\right)$} & \multicolumn{3}{|c|}{ Recovery (\%) } \\
\hline Acesulfame-K & Aspartame & Stevioside & Acesulfame-K & Aspartame & Stevioside & Acesulfame-K & Aspartame & Stevioside \\
\hline \multicolumn{9}{|c|}{ By PLS } \\
\hline 5.12 & 16.32 & 83.60 & 4.97 & 16.10 & 81.17 & 97.07 & 98.65 & 97.09 \\
\hline 4.16 & 18.94 & 40.53 & 4.44 & 19.35 & 43.60 & 106.73 & 102.16 & 107.57 \\
\hline 8.32 & 23.51 & 38.00 & 8.06 & 23.04 & 35.80 & 96.88 & 98.00 & 94.21 \\
\hline 11.20 & 7.84 & 91.20 & 11.20 & 7.97 & 90.48 & 100.00 & 101.66 & 99.21 \\
\hline 12.16 & 11.75 & 65.87 & 12.29 & 11.93 & 66.97 & 101.07 & 101.53 & 101.67 \\
\hline 7.68 & 9.79 & 53.20 & 7.64 & 9.94 & 55.80 & 99.48 & 101.53 & 104.89 \\
\hline 10.24 & 14.37 & 88.67 & 10.03 & 14.46 & 87.42 & 97.95 & 100.63 & 98.59 \\
\hline \multicolumn{9}{|c|}{ By siPLS } \\
\hline 5.12 & 16.32 & 83.60 & 5.16 & 16.10 & 83.80 & 100.83 & 98.63 & 100.24 \\
\hline 4.16 & 18.94 & 40.53 & 4.22 & 18.68 & 39.06 & 101.34 & 98.64 & 96.38 \\
\hline 8.32 & 23.51 & 38.00 & 8.17 & 23.19 & 36.77 & 98.14 & 98.64 & 96.76 \\
\hline 11.20 & 7.84 & 91.20 & 11.21 & 8.07 & 92.42 & 100.08 & 102.96 & 101.34 \\
\hline 12.16 & 11.75 & 65.87 & 12.39 & 12.10 & 68.53 & 101.88 & 102.95 & 104.04 \\
\hline 7.68 & 9.79 & 53.20 & 7.75 & 9.98 & 54.43 & 100.93 & 101.94 & 102.30 \\
\hline 10.24 & 14.37 & 88.67 & 10.05 & 14.52 & 88.50 & 98.12 & 101.06 & 99.81 \\
\hline
\end{tabular}


In order to test the applicability of the proposed analytical method to real samples, the analysis of different synthetic three-component acesulfame- $K$, aspartame and stevioside mixtures was carried out. The concentration of each component was chosen to be near its usual level in sweetener blends. The results obtained by applying the PLS and siPLS algorithm to seven synthetic samples are listed in Table 5. As can be seen in the table, the recovery of each compound was also quite acceptable.
The RMSEP and RSEP values for each compound in the prediction set are summarized in Table 6. It can be seen that the model using the selected variables by siPLS method presents better predictions with lower errors than the full PLS model. Again, it was demonstrated that a narrow spectrum region or their combination can be found by the siPLS algorithm for each substance with reduced variable numbers and small prediction errors.

Ta b l e 6

Statistical parameters for prediction set

\begin{tabular}{lccccc}
\hline \hline & \multicolumn{2}{c}{ PLS } & & \multicolumn{2}{c}{$\operatorname{siPLS}$} \\
\cline { 2 - 3 } \cline { 5 - 6 } \cline { 5 - 6 } & $\mathrm{RMSEP}^{a}$ & $\mathrm{RSEP}^{b}$ & & $\mathrm{RMSEP}^{a}$ & $\mathrm{RSEP}^{b}$ \\
\hline Acesulfame-K & 0.1817 & $2.05 \%$ & & 0.1330 & $1.50 \%$ \\
Aspartame & 0.2718 & $1.75 \%$ & & 0.2540 & $1.64 \%$ \\
Stevioside & 2.0778 & $3.01 \%$ & & 1.4041 & $2.03 \%$ \\
\hline \hline
\end{tabular}

${ }^{a}$ RMSEP $=$ relative standard error of prediction

${ }^{b} \mathrm{RSEP}=$ root mean square error of prediction

\section{CONCLUSION}

This study proves the feasibility of simultaneous spectroscopic determination of acesulfame potassium, aspartame and stevioside in raw powder mixtures. Partial least squares (PLS) and synergy interval PLS regression were applied to resolve the spectra overlapping. The siPLS algorithm demonstrated its ability to find out an optimized spectral region combination able to improve the performances of the corresponding PLS model. Lower prediction error and simplified calibration models were obtained. Our study proved the feasibility of simultaneous spectroscopic determination of acesulfame potassium, aspartame and stevioside in raw powder mixtures without the need of preliminary separation steps, and also demonstrated the usefulness of siPLS algorithm in multivariate food additives analysis for quality control tasks.
Acknowledgement: Financial support from the National Natural Science Foundation of the People's Republic of China (No. 21006094), Zhejiang Provincial Natural Science Foundation of China (No. Y4100708) and Educational Commission of Zhejiang Province of China (No. Y201016733) are gratefully acknowledged.

\section{REFERENCES}

[1] N.L. Matysiak and A.C. Noble, Comparison of temporal perception of fruitiness in model systems sweetened with aspartame, an aspartame + acesulfame K blend, or sucrose, J. Food Sci. 56, 823-826 (1991).

[2] M. Mukhopadhyay, A. Mukherjee and J. Chakrabarti, In vivo cytogenetic studies on blends of aspartame and acesulfame-K, Food Chem. Toxicol. 38, 75-77 (2000).

[3] S. S. Schiffman, E.A. Sattely-Miller and I. E. Bishay, Time to maximum sweetness intensity of binary and ternary blends of sweeteners, Food Qual. Pref. 18, 
405-415 (2007).

[4] A. B. Bergamo, J. da Silva and D. P. de Jesus, Simultaneous determination of aspartame, cyclamate, saccharin and acesulfame- $\mathrm{K}$ in soft drinks and tabletop sweetener formulations by capillary electrophoresis with capacitively coupled contactless conductivity detection, Food Chem. 124, 1714-1717 (2011).

[5] M. A. Cantarelli, R. G. Pellerano, E. J. Marchevsky and J. M. Camina, Simultaneous Determination of Saccharin and Aspartame in Commercial Noncaloric Sweeteners Using the PLS-2 Multivariate Calibration Method and Validation by Capillary Electrophoresis, J. Agric. Food Chem. 56, 9345-9349 (2008).

[6] Wasik, J. McCourt, and M. Buchgraber, Simultaneous determination of nine intense sweeteners in foodstuffs by high performance liquid chromatography and evaporative light scattering detection-Development and single-laboratory validation, J. Chromatogr. A 1157, 187-196 (2007).

[7] D. J. Yang and B. Chen, Simultaneous Determination of Nonnutritive Sweeteners in Foods by HPLC/ESIMS, J. Agric. Food Chem. 57, 3022-3027 (2009).

[8] P. Johns and L. Dowlati, Determination of acesulfame and sucralose in oral electrolyte maintenance solution by liquid chromatography, J. AOAC Int. 86, 79-85 (2003).

[9] Q. C. Chen, S. F. Mou, K. N. Liu, Z. Y. Yang and Z. M. Ni, Separation and determination of four artificial sweeteners and citric acid by high-performance anion-exchange chromatography, J. Chromatogr. A 771, 135-143 (1997).

[10] Y. Z. Zhang, Y. C. Zhou, L. Liu and Y. Zhu, Simultaneous determination of fluoride, chloride, sulfate, phosphate, monofluorophosphate, glycerophosphate, sorbate, and saccharin in gargles by ion chromatography, J. Zhejiang Univ. Sci. B 8, 507-511 (2007).

[11] J. Stroka, N. Dossi and E. Anklam, Determination of the artificial sweetener Sucralose $\AA$ by capillary electrophoresis, Food Addit. Contam. 20, 524-527 (2003).

[12] S. Armenta, S. Garrigues and M. de la Guardia, FTIR Determination of Aspartame and Acesulfame-K in Tabletop Sweeteners, J. Agric. Food Chem. 52, 7798-7803 (2004).

[13] Zygler, A. Wasik and J. Namieśnik, Analytical methodologies for determination of artificial sweeteners in foodstuffs, TrAC Trend. Anal. Chem. 28, 1082-1102 (2009).

[14] R. Gosselin, D. Rodrigue, C. Duchesne, A BootstrapVIP approach for selecting wavelength intervals in spectral imaging applications, Chemom. Intell. Lab. Syst. 100, 12-21 (2010).
[15] A. Coly, J. J. Aaron, Simultaneous determination of sulfonylurea herbicide synthetic binary mixtures by a partial least square method combined with micellar-enhanced photochemically-induced fluorescence application to tap water analysis, Maced. J. Chem. Chem. Eng. 27, 33-40 (2009).

[16] M. A. Cantarelli, R. G. Pellerano, E. J. Marchevsky and J.M. Camina, Simultaneous determination of aspartame and acesulfame-K by molecular absorption spectrophotometry using multivariate calibration and validation by high performance liquid chromatography, Food Chem. 115, 1128-1132 (2009).

[17] N. E. Llamas, M. S. Di Nezio, M. E. Palomeque and B.S. Fernández Band, Direct Determination of Saccharin and Acesulfame-K in Sweeteners and Fruit Juices Powders, Food Analytical Methods 1, 43-48 (2008).

[18] F. Turak, M. U. Ozgur and A. Bozdogan, PLS-UV Spectrophotometric Method for the Simultaneous Determination of Ternary Mixture of Sweeteners (Aspartame, Acesulfame-K and Saccharin) in Commercial Products, In: Sener, B. (ed), Innovations in Chemical Biology, Springer Publishers Ltd., Heidelberg, 2009, pp. 305-311.

[19] Y. N. Ni, W. Q. Xiao and S. Kokot, A differential kinetic spectrophotometric method for determination of three sulphanilamide artificial sweeteners with the aid of chemometrics, Food Chem. 113, 1339-1345 (2009).

[20] H. K. Khurana, I. K. Cho, J. Y. Shim, Q. X. Li and S. Jun, Application of multibounce attenuated total reflectance fourier transform infrared spectroscopy and chemometrics for determination of aspartame in soft drinks, J. Agric. Food Chem. 56, 778-783 (2008).

[21] S. Mazureka and R. Szostak, Quantification of aspartame in commercial sweeteners by FT-Raman spectroscopy, Food Chem. 125, 1051-1057 (2011).

[22] L. Xu and I. Schechter, Wavelength selection for simultaneous spectroscopic analysis. experimental and theoretical study, Anal. Chem. 68, 2392-2400 (1996).

[23] C. H. Spiegelman, M. J. McShane, M. J. Goetz, M. Motamedi, Q. L. Yue and G. L. Coti, Theoretical justification of wavelength selection in PLS calibration development of a new algorithm, Anal. Chem. 70, 35-44 (1998).

[24] J. H. Jiang, R. J. Berry, H. W. Siesler and Y. Ozaki, Wavelength interval selection in multicomponent spectral analysis by moving window partial leastsquares regression with applications to mid-infrared and nearinfrared spectroscopic data, Anal. Chem. 74, 3555-3565 (2002). 
[25] S. Fang, M. Q. Zhu and C. H. He, Moving window as a variable selection method in potentiometric titration multivariate calibration and its application to the simultaneous determination of ions in Raschig synthesis mixtures, J. Chemom. 23, 117-123 (2009).

[26] Y. P. Du, Y. Z. Liang, J. H. Jiang, R. J. Berry and Y. Ozaki, Spectral regions selection to improve prediction ability of PLS models by changeable size moving window partial least squares and searching combination moving window partial least squares, Anal. Chim. Acta 501, 183-191 (2004).

[27] L. Norgaard, A. Saudland, J. Wagner, J. P. Nielsen, L. Munck and S. B. Engelsen, Interval Partial LeastSquares Regression (iPLS): A Comparative Chemometric Study with an Example from Near-Infrared Spectroscopy, Appl. Spectrosc. 54, 413-419 (2000).

[28] R. Leardi and L. Nørgaard, Sequential application of backward interval PLS and Genetic Algorithms for the selection of relevant spectral regions, J. Chemom. 18, 486-497 (2004).

[29] M. Arakawa, Y. Yamashita and K. Funatsu, Genetic algorithm-based wavelength selection method for spectral calibration, J. Chemom. 25, 10-19 (2011).

[30] D. J. Rimbaud, D. L. Massart, R. Leardi and O.E.D. Noord, Genetic algorithms as a tool for wavelength selection in multivariate calibration, Anal. Chem. 67, 4295-4301 (1995).

[31] M. Shamsipur, V. Zare-Shahabadi, B. Hemmateenejad and M. Akhond, Ant colony optimisation: a powerful tool for wavelength selection, J. Chemom. 20, 146-157 (2006).

[32] V. Zare-Shahabadi, M. Shamsipur, B. Hemmatenejad and M. Akhond, Simultaneous Determination of Guaifenesin and Theophylline by Chemometrics Methods, Analyt. Lett. 43, 687-700 (2010).

[33] Q. Lu, M. J. Tang, J. R. Cai, H. Z. Lu and C. Sumpun, Selection of efficient wavelengths in NIR spectrum for determination of dry matter in kiwi fruit, Maejo Int. J. Sci. Technol. 4, 113-124 (2010).

[34] M. F. Ferrao, M. D. Viera, R. Pazos, D. Fachini, A. E. Gerbase and L. Marder, Simultaneous determination of quality parameters of biodiesel/diesel blends using HATR-FTIR spectra and PLS, iPLS or siPLS regressions, Fuel 90, 701-706 (2011).

[35] J. G. De Aguiar, A. Borin and R. J. Poppi, Determination of Viscosity and Solids in Pressure-Sensitive Adhesives by FTIR-ATR and Multivariate Calibration, J. Braz. Chem. Soc. 21, 436-440 (2010).

[36] Q. S. Chen, P. Jiang and J. W. Zhao, Measurement of total flavone content in snow lotus (Saussurea involucrate) using near infrared spectroscopy combined with interval PLS and genetic algorithm, Spectrochim. Acta, Part A 76, 50-55 (2010).

[37] Savitzky and M. J. E., Golay, Smoothing and differentiation of data by simplified least-squares procedures, Anal. Chem. 36, 1627-1639 (1964).

[38] Niazi, B. Jafarian and J. Ghasemi, Kinetic spectrophotometric determination of trace amounts of palladium by whole kinetic curve and a fixed time method using resazurine sulfide reaction, Spectrochim. Acta, Part A 71, 841-846 (2008).

[39] H. Parham, B. Aibaghi and J. Ghasemi, Simultaneous square wave voltammetric determination of 2-mercaptobenzothiazole and 2-mercaptobenzoxazole by partial least squares method in water samples, J. Hazard. Mater. 151, 636-641 (2008).

[40] J. Ghasemi and A. Niazi, Spectrophotometric simultaneous determination of nitroaniline isomers by orthogonal signal correction-partial least squares, Talanta 65, 1168-1173 (2005).

[41] G. W. Zhang and J. H. Pan, Simultaneous spectrophotometric determination of atrazine and cyanazine by chemometric methods, Spectrochim. Acta, Part A 78, 238-242 (2011).

[42] Y. N. Ni, Simultaneous determination of mixtures of acids by potentiometric titration, Anal. Chim. Acta 367, 145-152 (1998).

[43] K. Zarei, M. Atabati and Z. Malekshabani, Simultaneous spectrophotometric determination of iron, nickel and cobalt in micellar media by using direct orthogonal signal correction-partial least squares method, Anal. Chim. Acta 556, 247-254 (2006).

[44] D. M. Haaland and E. V. Thomas, Partial least squares methods for spectral analysis, Anal. Chem. 60, 1193-1202 (1988).

[45] G. Parisotto, M. F. Ferrao, A. Muller, E. I. Muller, M. Santos, R. Guimaraes, J. Dias and E. Flores, Total Acid Number Determination in Residues of Crude Oil Distillation Using ATR-FTIR and Variable Selection by Chemometric Methods, Energ. Fuel. 24, 5474-5478 (2010).

[46] F. Silva, M. F. Ferrao, G. Parisotto, E. I. Muller and E. M. M. Flores, Simultaneous determination of sulphamethoxazole and trimethoprim in powder mixtures by attenuated total reflection-Fourier transform infrared and multivariate calibration, J. Pharm. Biomed. Anal. 49, 800-805 (2009). 